\title{
Effect of Nutrient Removal and Resource Recovery on Life Cycle Cost and Environmental Impacts of a Small Scale Water Resource Recovery Facility
}

\author{
Ben Morelli ${ }^{1}\left(\right.$, Sarah Cashman ${ }^{1}$, Xin (Cissy) Ma ${ }^{2, *} \mathbb{C}$, Jay Garland ${ }^{3}$, Jason Turgeon ${ }^{4}$, \\ Lauren Fillmore ${ }^{5}$, Diana Bless ${ }^{2}$ and Michael $\mathrm{Nye}^{3}$ \\ 1 Eastern Research Group, 110 Hartwell Ave., Lexington, MA 02421, USA; ben.morelli@erg.com (B.M.); \\ sarah.cashman@erg.com (S.C.) \\ 2 United States Environmental Protection Agency, National Risk Management Research Laboratory, \\ 26 West Martin Luther King Drive, Cincinnati, OH 45268, USA; bless.diana@epa.gov \\ 3 United States Environmental Protection Agency, National Exposure Research Laboratory, \\ 26 West Martin Luther King Drive, Cincinnati, OH 45268, USA; garland.jay@epa.gov (J.G.); \\ nye.michael@epa.gov (M.N.) \\ 4 United States Environmental Protection Agency, Region 1, 5 Post Office Square, Suite 100, OEP 5-2, Boston, \\ MA 02109, USA; turgeon.jason@epa.gov \\ 5 Water Research Foundation, 1199 N Fairfax Street, Suite 900, Alexandria, VA 22314, USA; \\ laurenfillmore@wildblue.net \\ * Correspondence: ma.cissy@epa.gov; Tel.: +1-513-569-7828
}

Received: 6 September 2018; Accepted: 28 September 2018; Published: 3 October 2018

\begin{abstract}
To limit effluent impacts on eutrophication in receiving waterbodies, a small community water resource recovery facility (WRRF) upgraded its conventional activated sludge treatment process for biological nutrient removal, and considered enhanced primary settling and anaerobic digestion (AD) with co-digestion of high strength organic waste (HSOW). The community initiated the resource recovery hub concept with the intention of converting an energy-consuming wastewater treatment plant into a facility that generates energy and nutrients and reuses water. We applied life cycle assessment and life cycle cost assessment to evaluate the net impact of the potential conversion. The upgraded WRRF reduced eutrophication impacts by $40 \%$ compared to the legacy system. Other environmental impacts such as global climate change potential (GCCP) and cumulative energy demand (CED) were strongly affected by $\mathrm{AD}$ and composting assumptions. The scenario analysis showed that HSOW co-digestion with energy recovery can lead to reductions in GCCP and CED of $7 \%$ and $108 \%$, respectively, for the upgraded WRRF (high feedstock-base AD performance scenarios) relative to the legacy system. The cost analysis showed that using the full digester capacity and achieving high digester performance can reduce the life cycle cost of WRRF upgrades by $15 \%$ over a 30-year period.
\end{abstract}

Keywords: LCA; LCCA; wastewater treatment; anaerobic digestion; biogas; resource recovery; nutrient removal; water-energy-nutrient nexus

\section{Introduction}

Urban water systems have been evolving as the industrial market economy grows. During the last century, cities in the U.S. and around the world have implemented municipality-run water management approaches to resolve sanitary and freshwater supply issues [1]. Wastewater has been treated as waste to be eliminated with the investment of large amounts of energy and materials, regardless of the potential values of wastewater constituents. In recent decades, many municipalities are facing 
deteriorating water quality in water bodies due to eutrophication and pollution from point-sources such as effluents from wastewater treatment facilities. In response, the U.S. Environmental Protection Agency (U.S. EPA) has implemented more stringent effluent quality standards [2]. In addition, much of the wastewater treatment infrastructure is in dire need of improvement due to age, wear, and tear. In 2013, the American Society of Civil Engineers' Infrastructure Report Card assigned both drinking water and wastewater infrastructures a grade of $\mathrm{D}^{+}$, indicating a considerable backlog of overdue maintenance and a pressing need for modernization [3]. With a growing population facing increased regulatory requirements, resource constraints, and financial challenges, communities are seeking more comprehensive and sustainable solutions to address multiple environmental challenges and maximize the recovery of water, energy, nutrients, and materials [1,4,5]. Municipal wastewater and other high strength organic wastes (HSOW) generated in cities are now regarded as a resource for water, energy, and nutrients [6-10].

However, the environmental sustainability of wastewater systems goes beyond the treatment plants. It has been argued that many impacts occur at a larger watershed level or along upstream supply chains during energy, chemical, and material production [11,12]. These complex water issues are inherently intertwined and cannot be solved by traditional siloed water management approaches [1]. It is necessary to apply system-based tools or metrics and integrated assessment frameworks such as life cycle assessment (LCA) and life cycle cost assessment (LCCA) to measure trade-offs and develop optimized solutions $[5,13]$.

With increased environmental and financial resources at stake in these more complex processes, the U.S. EPA research team intends to explore how best to meet a set of goals that often seem contradictory. The effluent quality improvement associated with more stringent standards for nutrient removal may often be achieved at the expense of increases in energy use, chemical inputs, and system costs. When communities are required to improve nutrient removal to reduce eutrophication in receiving waterbodies, system analyses can help identify environmentally efficient and cost-effective options and incentivize utilities to strive for energy self-sufficiency.

Driven by the changes in regulatory nutrient permit limits instituted by the Chesapeake Bay Watershed Cleanup Initiative, the Village of Bath, New York and Bath Electric, Gas \& Water Systems (BEGWS) proposed the resource recovery hub concept to move its traditional wastewater industry in a new cost-effective direction. BEGWS' goal was conversion of an energy-consuming wastewater treatment plant into a water resource recovery facility (WRRF) [14] that generates energy and reuses water and nutrients to improve the resiliency, reliability and revenue of the local electrical and water supply while reducing the environmental footprint of the facility and the watershed.

BEGWS proposed a system upgrade ("upgraded system") from a "legacy system" for enhanced nutrient removal to reach a summer time permit limit of $3.6 \mathrm{mg} / \mathrm{L}$ ammonia nitrogen. The potential retrofitted WRRF in Bath, NY provided a unique opportunity as a testbed to evaluate transformative technologies and holistic solutions to water, energy, nutrient, and solid waste resource challenges. In this study, LCA and LCCA tools were used: (1) to evaluate the comparative environmental benefits and burdens associated with the legacy and upgraded systems; and (2) to determine the energy recovery potential of the upgraded systems including co-digestion of HSOW and the cost benefits of offsetting energy use.

The focus of this study was the WRRF in Bath, NY (approximately 5600 people). The facility has a permitted flow capacity of 1 million gallon per day (MGD) (3800 $\mathrm{m}^{3} /$ day) [15] and discharges effluent into the Cohocton River, which empties into the Chesapeake Bay potentially impacting sensitive habitats [16]. Figure 1 shows the LCA system boundaries for the legacy and upgraded WRRFs. Foreground unit processes refer to WRRF and end-of-life (EOL) unit processes for which life cycle inventory (LCI) data were developed as a part of this project. Background unit processes refer to upstream material and energy production processes for which LCI data were drawn from existing databases, as discussed in Section 2.2. 


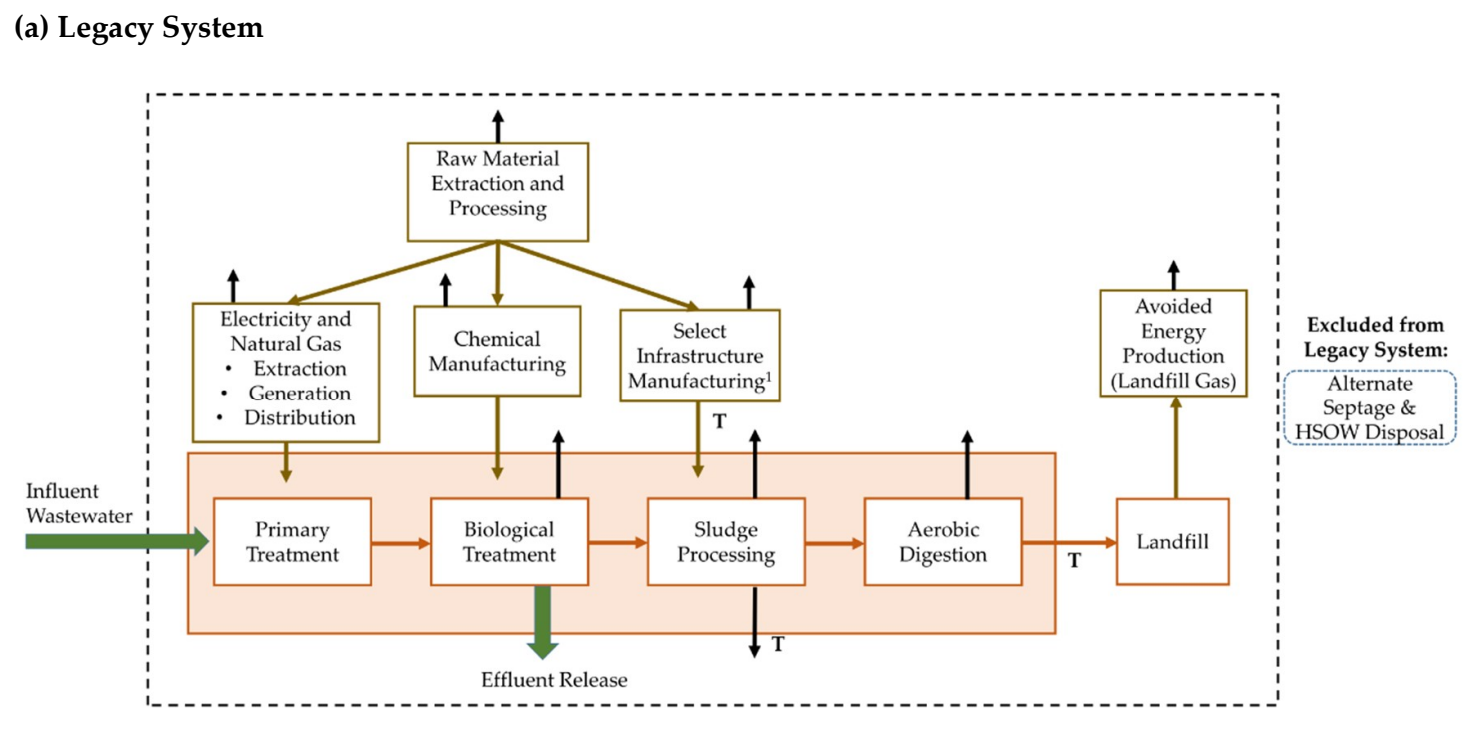

(b) Upgraded System

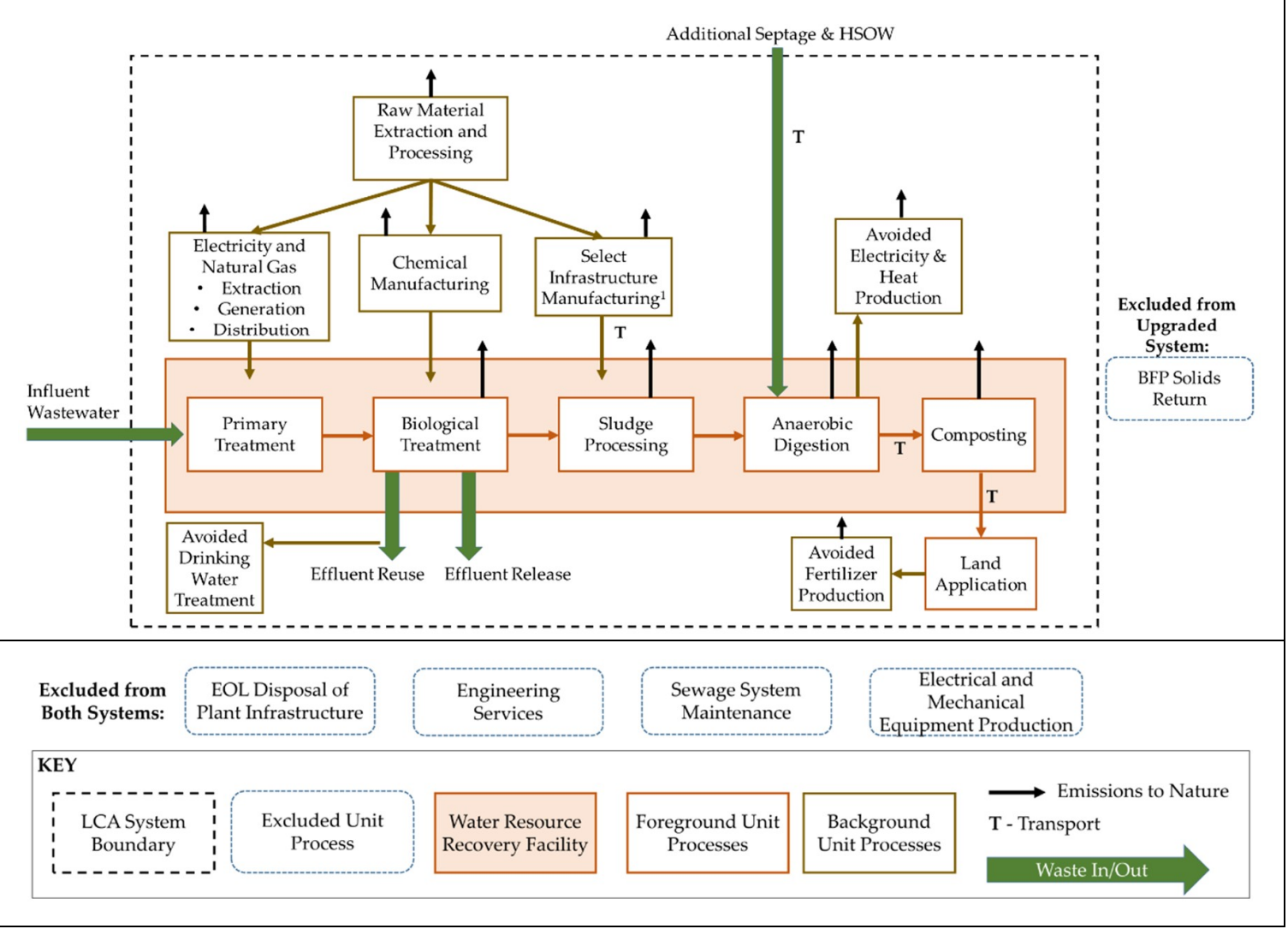

Figure 1. System diagrams for the (a) Legacy and (b) Upgraded water resource recovery facilities. The infrastructure constitutes the concrete, structural steel, and aggregate required for unit process and building construction. Abbreviations: BFP, belt filter press; EOL, end-of-life; HSOW, high strength organic waste; LCA, life cycle assessment.

The legacy WRRF configuration represents the treatment process that had been in place since 1993, and it is a typical example of conventional activated sludge (CAS) treatment in use throughout the U.S. (Figure S1). The plant headworks consisted of a mechanical bar screen, comminutors, a grit well, and a Parshall flume. Solids were removed via primary settling and secondary clarification, aided by a 
polyaluminum chloride (PAC) flocculent, added prior to aeration. The effluent was discharged without disinfection. Primary solids and waste activated sludge (WAS) was subjected to gravity thickening, which was in turn aerobically digested for solids stabilization and dewatering via a belt filter press (BFP) before trucking and disposal in a local landfill [17]. The Bath regional landfill is equipped with a methane capture system designed to achieve a 95\% capture rate for use in a waste-to-energy (WTE) facility [18].

The upgraded WRRF is a renovation of the legacy facility. BEGWS is exploring the option of chemically enhanced primary settling in combination with a Modified-Ludzack Ettinger (MLE) biological treatment system for nitrogen removal. The facility is also considering expanding its receipt of residential septage and HSOW for processing in the proposed anaerobic digester (AD). Locally available forms of HSOW include cheese processing and slaughterhouse waste from regional food processing facilities. Septage waste is trucked to the facility by companies collecting septic tank and portable toilet waste in the Bath region. These proposed options in combination with the currently installed MLE system compose the modeled upgraded WRRF. Ferric chloride is used to enhance solids captured in the primary clarification system and is paired with a screen compaction press for grit removal and gravity belt thickening (GBT) for dewatering of primary solids and WAS (Figure S2). The legacy aerobic digester was repurposed to provide a pre-anoxic and swing tank for nitrogen removal prior to aeration, creating an MLE biological treatment process. The MLE treatment process is a common method of biological nutrient removal that relies on facultative bacteria in the anoxic zone to remove nitrogen by using organic matter as an electron donor for denitrification [19]. The swing tank can be run in aerobic or anoxic mode depending upon operational requirements.

The combined municipal sludge stream is blended with incoming septage and HSOW before introduction to the two-stage mesophilic AD facility. The first AD tank is completely mixed and heated to $35{ }^{\circ} \mathrm{C}$. An internal combustion engine based combined heat and power (CHP) system is used to generate electricity and thermal energy for subsequent sale to the local grid and for internal facility use [17]. Digested solids are thickened via BFP and trucked a short distance $(0.8 \mathrm{~km})$ to an on-site windrow composting facility where solids are combined with locally available organic materials to achieve the appropriate $\mathrm{C}: \mathrm{N}$ ratio and moisture content for successful composting. Finished Class A compost is screened and cured prior to trucking to local agricultural fields where it is used as an agricultural amendment and fertilizer replacement.

While LCAs have been previously conducted on small scale wastewater treatment facilities $[20,21]$ and sewage sludge co-digestion with HSOW [22-25], our study is the first effort that comprehensively explores how a small traditional wastewater facility in the U.S. can be retrofitted into a more sustainable resource recovery hub. According to U.S. EPA's estimate, approximately $72 \%$ of the operational public wastewater treatment facilities (over 11,000) in the U.S. are considered "small systems" [26]. This study applied a range of input and output parameters likely to correspond to those observed in other communities. The results of the scenarios considered here may have implications for these utilities. Our intent is to provide a comprehensive and flexible suite of environmental and cost indicators to encourage small scale wastewater utility decision makers to start thinking more systematically when dealing with issues unique to their cities or communities.

\section{Methods}

This study used the LCA methodology, following guidelines outlined in ISO 14044 [27], to generate comparative LCA results for two WRRF configurations under several operational scenarios. The basis of the system comparison, known as the functional unit, was one cubic meter of wastewater treated to the effluent qualities defined in Table 1. The comparative scenarios represent before and after conditions for a 1 MGD $\left(3800 \mathrm{~m}^{3}\right.$ /day) CAS WRRF that underwent the proposed upgrades to its secondary biological treatment unit to reach enhanced effluent quality, while simultaneously employing resource recovery strategies such as $\mathrm{AD}$ and composting. Upgrades were required because the legacy WRRF was not able to meet updated nitrogen permit limits. Differences in effluent quality 
are reflected in the environmental analysis. For the upgraded WRRF, feedstock scenarios were developed to understand the environmental and cost impact of co-digesting varying quantities of septage and HSOW. For all scenarios, the LCI was developed by dividing annual flows of input materials (e.g., chemicals and energy) by the influent flowrate of 1 MGD $\left(3800 \mathrm{~m}^{3} /\right.$ day), standardizing $\mathrm{LCI}$ values per cubic meter of treated wastewater. The change in facility flowrate associated with HSOW feedstock scenarios was excluded from the standardization calculation as HSOW contributes minorly $(<2.5 \%)$ to overall volumetric flow. Infrastructure material inputs were also originally calculated on an annual basis and then standardized per cubic meter of treated wastewater by allocating equally over their useful lifespan. We did not evaluate the environmental impacts of alternative treatment options for HSOW within the legacy scenario, due to a lack of information about current treatment methods. This exclusion could affect relative impact between the legacy and upgraded WRRFs. The functional unit formulation facilitates comparison of facility level treatment impacts encompassing the changes in system layout, waste acceptance, and operational performance. LCCA was used to evaluate the net present value (NPV) of the upgraded WRRF across all feedstock and AD performance scenarios.

Table 1. Influent and effluent wastewater characterization.

\begin{tabular}{cccccc}
\hline Characteristic & Influent [28] & $\begin{array}{c}\text { Effluent, } \\
\text { Legacy [28] }\end{array}$ & $\begin{array}{c}\text { Effluent, } \\
\text { Upgraded [17] }\end{array}$ & $\begin{array}{c}\text { Effluent, } \\
\text { Permitted [15] }\end{array}$ & Units \\
\hline Suspended Solids & 437 & 7.9 & 5 & 30 & $\mathrm{mg} / \mathrm{L}$ \\
CBOD $_{5} 1$ & 279 & 7.4 & 2 & 25 & $\mathrm{mg} / \mathrm{L}$ \\
Total Kjeldahl Nitrogen & 56 & 16 & 4.4 & $\mathrm{n.a.}{ }^{2}$ & $\mathrm{mg} / \mathrm{L} \mathrm{N}$ \\
Ammonia & 32 & 6.7 & 3.6 & $3.6^{3}$ & $\mathrm{mg} / \mathrm{L} \mathrm{NH} 3$ \\
Total Phosphorus & 8 & 0.7 & 0.6 & 0.6 & $\mathrm{mg} / \mathrm{L} \mathrm{P}$ \\
Nitrite & $<1$ & 2.8 & 0.8 & n.a. ${ }^{2}$ & $\mathrm{mg} / \mathrm{L} \mathrm{N}$ \\
Nitrate & $<1$ & 13 & 14 & n.a. ${ }^{2}$ & $\mathrm{mg} / \mathrm{L} \mathrm{N}$ \\
Organic Nitrogen & 29 & 9 & 0.8 & n.a. ${ }^{2}$ & $\mathrm{mg} / \mathrm{L} \mathrm{N}$ \\
Total Nitrogen & 57 & 31 & 20 & 20 & $\mathrm{mg} / \mathrm{L} \mathrm{N}$ \\
\hline
\end{tabular}

${ }^{1}$ Carbonaceous biochemical oxygen demand; ${ }^{2}$ n.a., not applicable, not a permitted value; ${ }^{3}$ monthly average summertime permit limit. Winter value is $8.4 \mathrm{mg} / \mathrm{L}$ ammonia.

\subsection{Scenario Analysis}

The study employed scenario and sensitivity analyses to test LCA and LCCA results over a range of input and output parameters likely to correspond to those observed in similar communities. We defined low (base), medium, and high scenarios for the acceptance of AD co-digestion feedstock (Table 2). Low, base, and high scenarios were defined for AD operational performance and EOL emission rates, with associated parameter values listed in Tables 3 and 4. The EOL emission scenarios only pertain to greenhouse gases (GHG) generated in the landfill (legacy WRRF) or during composting (upgraded WRRF). In total, results were generated for 6 and 54 scenario combinations for the legacy and upgraded treatment systems, respectively (Tables S1 and S2).

Table 2. Feedstock scenario parameter values.

\begin{tabular}{cccccc}
\hline \multirow{2}{*}{ Feedstock Type $^{1}$} & Legacy $^{2}$ & Low (Base) & Medium & High & \multirow{2}{*}{ Units } \\
\cline { 2 - 5 } & \multicolumn{5}{c}{ Feedstock Quantity } \\
Primary Sludge & 67 & 71 & 71 & 71 & $\mathrm{~m}^{3} / \mathrm{day}^{3}$ \\
Waste Activated Sludge & 290 & 300 & 300 & 300 & $\mathrm{~m}^{3} / \mathrm{day}^{2}$ \\
Septage & 30 & 61 & 61 & 61 & $\mathrm{~m}^{3} / \mathrm{day}^{3}$ \\
High Strength Organic Waste & - & - & 15 & 30 & $\mathrm{~m}^{3} /$ day \\
\hline
\end{tabular}

${ }^{1}$ Feedstock quantity values are presented prior to dewatering. ${ }^{2}$ The quantity of solids processed by the legacy system remains constant. Legacy values are provided as a comparison to the upgraded WRRF AD feedstock scenarios. * Designates the parameter values associated with the base, upgraded results scenario. 
The AD system designed for the treatment plant upgrade is oversized for the solids processing needs for municipal wastewater alone. The feedstock scenarios test the effect of using the excess AD capacity to process additional septage and HSOW. The legacy treatment system did not include AD. Table 2 shows the quantity of waste feedstock prior to dewatering from each source category destined for digestion. HSOW does not require dewatering and consists of industrial cheese waste, slaughterhouse waste, and winery waste available in the region. HSOW characteristics are documented in Table S3.

Low, base, and high estimates of AD performance were examined for their effects on biogas production and associated environmental and cost benefits and burdens. We selected parameter values to represent a reasonable range of $\mathrm{AD}$ operational performance as documented in the literature and summarized in Table 2. Biogas yield values were calculated as a weighted average of feedstock-specific biogas yield estimates reported in Table S4.

The carbon and nitrogen content of AD biosolids impact GHG emissions produced during landfilling or composting and land application of these materials. Low, base, and high estimates of potential composting and landfill emission rates were evaluated. The analysis evaluates both windrow and aerated static pile (ASP) composting systems. We calculated impacts assuming methane capture rates characteristic of the Bath regional landfill, 95\% [18], and a national average landfill methane capture rate of $57 \%$ [29]. Landfill methane emissions were calculated over a 100-year period using a first-order decay equation and parameter values presented in Table 3 [30]. A landfill carbon storage credit was applied to the non-degradable carbon and the fraction of degradable carbon that remains after 100 years. Degradation rates approximate conditions that range from cold and dry (low) to warm and moist (high), depending on the emission scenario [30].

Table 3. Upgraded WRRF anaerobic digester performance scenarios.

\begin{tabular}{|c|c|c|c|c|}
\hline \multirow{2}{*}{$\begin{array}{c}\text { Anaerobic Digestion } \\
\text { Parameter }\end{array}$} & Low & Base * & High & \\
\hline & \multicolumn{3}{|c|}{ AD Performance } & Units \\
\hline Loading Rate $^{1}$ & 220 & 270 & 350 & $\mathrm{~kg} \mathrm{VS} / \mathrm{m}^{3} /$ day \\
\hline Biogas Yield ${ }^{2}$ & 0.75 & 0.94 & 2.2 & $\begin{array}{l}\mathrm{m}^{3} / \mathrm{kg} \text { VS } \\
\text { destroyed }\end{array}$ \\
\hline Volatile Solids Reduction [31] & 45 & 60 & 65 & $\%$ \\
\hline Methane Content of Biogas [32] & 60 & 65 & 70 & $\% \mathrm{v} / \mathrm{v}$ \\
\hline Biogas Heat Content [32] & 0.55 & 0.59 & 0.61 & $\mathrm{MJ} / \mathrm{ft}^{3}$ \\
\hline CHP Electrical Efficiency & $30[32]$ & 36 [17] & $42[32]$ & $\%$ \\
\hline CHP Thermal Efficiency & $41[32]$ & $51[17]$ & $43[32]$ & $\%$ \\
\hline
\end{tabular}

Base results for the legacy treatment system are defined by the base EOL emission assumptions and a methane capture rate characteristic of the Bath regional landfill. Base results for the upgraded treatment system are defined by base parameter values for the feedstock, AD performance, and EOL emission scenarios assuming the use of windrow composting. Base scenarios are intended to serve as a benchmark for comparison against the sensitivity scenarios. The base scenario for the upgraded treatment plant does not include co-digestion of HSOW and assumes typical, achievable values for $\mathrm{AD}$ performance and biogas generation. Base EOL emission estimates are in the middle of the reported range. 
Table 4. EOL greenhouse gas emissions scenarios for the legacy and upgraded WRRFs.

\begin{tabular}{|c|c|c|c|c|}
\hline EOL Treatment Option & Low & Base * & High & \\
\hline Landfill—with Methane Capture ${ }^{1}$ & \multicolumn{3}{|c|}{ GHG Emissions } & Units \\
\hline Carbon Content of Dry Solids & $38[33]$ & 48 & $57[33]$ & $\%$ \\
\hline Degradable Organic Carbon [30] & 5.0 & 5.0 & 5.0 & $\%$ wet mass ${ }^{2}$ \\
\hline Degradable Carbon Decomposed [33] & 50 & 65 & 80 & $\%$ \\
\hline Degraded Carbon to $\mathrm{CH}_{4}[30,33]$ & 50 & 50 & 50 & $\%$ \\
\hline Methane to $\mathrm{CO}_{2}$ in landfill cover [33] & 25 & 10 [30] & 3 & $\%$ \\
\hline $\mathrm{k}$, degradation rate & 0.10 & 0.18 & 0.23 & unitless \\
\hline EOL Treatment Option & Low & Base * & High & \\
\hline Composting $^{3}$ & \multicolumn{3}{|c|}{ GHG Emissions } & Units \\
\hline $\mathrm{CH}_{4}$ Emissions ${ }^{4}$ & $0.11[34]$ & 0.82 & $2.5[35]$ & $\%$ incoming $\mathrm{C}$ \\
\hline $\mathrm{N}_{2} \mathrm{O}$ Emissions ${ }^{5}$ & $0.34[34]$ & 2.7 & $4.7[36]$ & $\%$ incoming $\mathrm{N}$ \\
\hline
\end{tabular}

${ }^{1}$ The landfill EOL treatment option is only associated with the legacy WRRF. ${ }^{2}$ The BFP produces dewatered biosolids with a solids content of $20 \%$ for trucking to the landfill. ${ }^{3}$ The compost EOL treatment option is only associated with the upgraded WRRF. ${ }^{4}$ Methane emissions are assumed to be zero for covered aerated static pile (ASP) system with biofilter [33]. ${ }^{5}$ Nitrous oxide emissions are the same for both ASP and windrow composting. * Designates the parameter values associated with the base results scenarios. Abbreviations: C, carbon; EOL, end-of-life; $\mathrm{N}$, nitrogen.

\subsection{Life Cycle Inventory Model}

Construction and operation LCI data for the legacy WRRF were provided by facility staff. Historic data for an average annual flowrate of $0.67 \mathrm{MGD}\left(2500 \mathrm{~m}^{3} /\right.$ day $)$ were used. Electricity and chemical use were scaled to account for the 1 MGD ( $3800 \mathrm{~m}^{3} /$ day) basis of this analysis. We used the NY regional electrical grid mix to estimate the environmental impact of electricity consumption and the environmental benefit of avoided electricity production (Table S5). Electricity use for plant equipment was calculated based on mechanical equipment horsepower or voltage and current draw for each piece of equipment as demonstrated, in (Supporting Information (SI) Section S1.5. Estimates of material use for major infrastructure elements were calculated using dimensions from facility blueprints. Quantities of earthwork, concrete, steel, polyvinyl chloride (PVC), and gravel were estimated for the following units: (1) Parshall flume; (2) primary settling tank; (3) wet well; (4) aeration basins; (5) aerobic digester; (6) sludge thickener; (7) inter-unit piping; (8) control buildings; and (9) collection system piping. Materials associated with mechanical equipment such as pumps, mixers, and boilers were excluded from the analysis.

Equipment and infrastructure information carried over from the legacy WRRF was supplemented with additional equipment and energy requirements available in engineering design documents to represent the upgraded WRRF [17]. We estimated infrastructure for the chemically enhanced primary clarification unit and of the receiving station using basic unit dimensions and assuming similar construction methods required by other units. Infrastructure estimates for the primary and secondary digesters were calculated using CAPDETWorks ${ }^{\mathrm{TM}}$ engineering design and costing software [37].

We scaled equipment electricity use for the upgraded WRRF for sludge processing units affected by the feedstock scenarios based on the change in volumetric flow, mass flow rate, or loading rate as appropriate. For example, the increase in BFP electricity use required for the high feedstock scenario was based on the additional equipment operation time required to process the increased volume of digested sludge. Table $\mathrm{S} 6$ lists the scaling factors, applied to the base electricity consumption values, used to estimate electricity consumption for each feedstock-AD scenario. The legacy and upgraded treatment systems both consume PAC and polymer as flocculation and dewatering aids, respectively. The upgraded treatment system also uses ferric chloride for chemically enhanced primary clarification. Polymer consumption was calculated from dosage rates applied per the quantity of solids processed, which varies for the upgraded WRRF according to feedstock scenario (Tables S7 and S8). SI Section S1.6 details the calculations used to estimate LCI chemical quantities. We calculated the increased 
energy requirement for secondary aeration based on the additional BOD and $\mathrm{N}$ loading to secondary treatment associated with $\mathrm{AD}$ and BFP supernatant. An oxygen demand factor of $4.25 \mathrm{~kg} \mathrm{O}_{2}$ per $\mathrm{kg}$ of $\mathrm{NH}_{3}$ nitrified was used to calculate the energy requirement of $\mathrm{N}$ loading [38].

We determined GHG emissions from legacy and upgraded secondary treatment processes and aerobic digestion from influent TKN and BOD concentrations, which vary across feedstock scenarios. We assumed $0.035 \%$ of nitrogen influent to each unit is released as nitrous oxide [39]. Methane emissions were calculated using a theoretical maximum methane generation rate of $0.6 \mathrm{~kg} \mathrm{CH} / \mathrm{kg}$ influent BOD, which reflects methane emissions under anaerobic conditions [40]. We adjusted the theoretical maximum downwards using a methane correction factor of 0.005 , which reflects the potential for methane production in small pockets of anaerobic conditions. The CAS methane correction factor is on the same order of magnitude as that calculated based on data from Czepiel et al. (1993) [41], and is on the low end of the IPCC's reported uncertainty range of 0 to 0.1 for a well-managed aerobic treatment plant [40]. For the MLE system with zones for both nitrification and denitrification, the same approach was applied using a methane correction factor of 0.05 [42]. For the MLE unit, we assumed that $0.16 \%$ of influent nitrogen is lost as nitrous oxide [43]. Nitrous oxide emissions from receiving streams for both systems were calculated based on the IPCC guideline that $0.005 \mathrm{~kg}$ of $\mathrm{N}_{2} \mathrm{O}-\mathrm{N}$ are emitted per $\mathrm{kg}$ of nitrogen discharged to the aquatic environment [40]. The methodology used to calculate landfill GHG emissions is presented in Section 2.1, and further details on each GHG calculation method can be found in SI Section S1.7.

The legacy WRRF was credited with avoided electricity use for the share of landfill methane delivered to the WTE facility assuming an electrical conversion efficiency of $29 \%$. Table S9 lists additional statistics concerning methane capture or release at the Bath regional and national average landfills. Avoided electricity and natural gas use associated with the upgraded WRRF is a product of biogas recovery (Table S10) and varies depending upon the feedstock-AD scenario under consideration (Tables S11-S13). Table S14 lists the additional quantity of natural gas that is required to provide facility and digester heat beyond that provided by biogas combustion. AD fugitive methane emissions were estimated assuming a 1\% methane loss both from the digesters and CHP engine (Tables S15 and S16). An avoided fertilizer production credit was applied to the upgraded WRRF based on N and P content of the composted biosolids assuming a fertilizer replacement value of 73\% [44]. Approximately $4 \%$ of annual treated effluent was assumed to be reused for irrigation at a local golf course during the summer months.

We constructed the LCI model using unit process and elementary flow data drawn from the U.S. EPA's harmonized version of the U.S. LCI [45] and Ecoinvent 2.2 LCI databases [46]. Elementary flows are flows of material (emissions) and energy both to and from nature. They include process and combustion emissions associated with upstream material extraction, industrial processing, manufacturing, transportation, and EOL disposal in addition to the specific elements of the foreground LCI model described here. Summarized system-level LCI quantities for the legacy and upgraded treatment systems are presented in Table 5. 
Table 5. Inventory of principal material and energy flows by treatment stage for legacy and upgraded base scenarios.

\begin{tabular}{|c|c|c|c|c|c|c|c|c|c|c|}
\hline \multirow{3}{*}{ Treatment Stage } & \multicolumn{4}{|c|}{ Material and Energy Inputs 1} & \multicolumn{2}{|c|}{ Process Emissions } & \multicolumn{4}{|c|}{ Avoided Products } \\
\hline & Electricity & Natural Gas & Transport & Chemicals & Methane & Nitrous Oxide & Electricity & Natural Gas & Fertilizer & Effluent Reuse \\
\hline & $\mathrm{kWh} / \mathrm{m}^{3}$ & $\mathrm{MJ} / \mathrm{m}^{3}$ & $\mathrm{tkm} / \mathrm{m}^{3}$ & $\mathrm{~kg} / \mathrm{m}^{3}$ & $\mathrm{~kg} / \mathrm{m}^{3}$ & $\mathrm{~kg} / \mathrm{m}^{3}$ & $\mathrm{kWh} / \mathrm{m}^{3}$ & $\mathrm{MJ} / \mathrm{m}^{3}$ & $\mathrm{~kg} / \mathrm{m}^{3}$ & $\mathrm{~m}^{3} / \mathrm{m}^{3}$ \\
\hline \multicolumn{11}{|c|}{ Legacy WRRF (Base Scenario) } \\
\hline Primary Treatment & 0.15 & - & - & 0.55 & - & - & - & - & - & - \\
\hline Secondary Treatment & 0.36 & - & - & - & $6.3 \times 10^{-4}$ & $2.5 \times 10^{-5}$ & - & - & - & - \\
\hline Sludge Processing & 0.39 & - & - & $5.4 \times 10^{-4}$ & 2. $4 \times 10^{-3}$ & $5.7 \times 10^{-5}$ & - & - & - & - \\
\hline End-of-Life & - & - & 0.05 & - & 0.02 & $6.1 \times 10^{-4}$ & 0.09 & - & - & - \\
\hline Effluent Release & $9.3 \times 10^{-5}$ & - & - & - & - & $2.5 \times 10^{-4}$ & - & - & - & - \\
\hline Facilities & - & 0.71 & - & - & - & - & - & - & - & - \\
\hline Total & 0.90 & 0.71 & 0.05 & 0.55 & 0.02 & $9.4 \times 10^{-4}$ & 0.09 & - & - & - \\
\hline \multicolumn{11}{|c|}{ Upgraded WRRF (Base Scenario) } \\
\hline Primary Treatment & 0.32 & - & - & 0.03 & - & - & - & - & - & - \\
\hline Secondary Treatment & 0.61 & - & - & $4.8 \times 10^{-3}$ & $5.3 \times 10^{-3}$ & $1.1 \times 10^{-4}$ & - & - & - & 0.04 \\
\hline Sludge Processing & 0.38 & 0.56 & 0.40 & $5.0 \times 10^{-3}$ & 1. $8 \times 10^{-3}$ & - & 0.45 & 2.2 & - & - \\
\hline End-of-Life & $5.5 \times 10^{-4}$ & - & 0.05 & - & 0.01 & $1.7 \times 10^{-3}$ & - & - & 0.03 & - \\
\hline Effluent Release & 0.03 & - & - & - & - & $1.5 \times 10^{-4}$ & - & - & - & - \\
\hline Facilities & - & 1.1 & - & - & - & - & - & - & - & - \\
\hline Total & 1.3 & 1.7 & 0.45 & 0.04 & 0.02 & $2.0 \times 10^{-3}$ & 0.45 & 2.2 & 0.03 & 0.04 \\
\hline
\end{tabular}

${ }^{1}$ This table excludes infrastructure materials and aggregates chemical and fertilizer use on a mass basis. 


\subsection{Life Cycle Impact Assessment}

Life cycle impact assessment (LCIA) is the stage in an LCA study in which elementary flows in the LCI associated with the entire supply chain are characterized to estimate environmental impacts. This paper presents impact results for eutrophication potential (EP), 100-year global climate change potential (GCCP), water use (WU), and cumulative energy demand (CED). WU and CED are inventory indicators and do not require characterization, but still include both direct and indirect resource use. GCCP and EP are calculated per the TRACI 2.1 method for the U.S. geographic context [47,48]. EP characterizes both nitrogen and phosphorus releases and is therefore generalized to be relevant for both freshwater and marine contexts. Water use was calculated using ReCiPe 2008 [49] and excluded turbine water use and evaporative loss from hydroelectricity. CED is calculated using the methodology developed for implementation in Ecoinvent 2.2 [50]. Because biogas enters the facility as a waste product, its energy content is not included in the CED calculation as CED is intended to estimate energy withdrawn from nature.

All process carbon dioxide emissions during wastewater or EOL treatment were modeled as biogenic in origin and do not contribute to GCCP. We did, however, estimate the fraction of carbon that is converted to methane, which contributes to GCCP. Carbon credits were attributed to both the legacy and upgraded WRRFs for the fraction of carbon either in landfill or agricultural fields that remains sequestered for over 100 years. Avoided products associated with energy recovery, compost use, and treated effluent reuse generate environmental credits that reduce net environmental impact and were tracked as negative values. The term gross environmental impact is used to refer to the total impact results in the absence of environmental credits.

LCIA results were also generated for particulate matter formation potential, smog formation potential, acidification potential, and fossil depletion potential. LCIA methods used for these additional impact categories are listed in Table S17. We provide results for the additional impact categories in a supplementary Bath WRRF Results File.

\subsection{Life Cycle Cost Assessment}

The LCCA tabulates financial expenditures and revenue over a 30-year period using a NPV calculation to determine total project costs in present dollars. Life cycle costs for the upgraded WRRF and payback period of the AD system were calculated using three sets of LCCA parameters yielding low, base, and high estimates of system NPV (Table S18). No LCCA is performed for the legacy system since it is no longer a viable design due to changes in permit requirements. We applied the three cost scenarios to each of the nine feedstock-AD performance scenarios to estimate a reasonable NPV range for each LCA scenario. A payback period was only calculated for the AD system as other unit processes generate no direct revenue. In the case of Bath NY, installation of MLE advanced secondary treatment is required to meet effluent quality standards and is not based on economic rationale.

Main data sources for the analysis include historical budget data for the legacy WRRF. A previous LCCA study was carried out by GHD Inc. engineering for upgrades to primary clarification and secondary treatment, and relevant cost data were incorporated into this assessment [51]. We used CAPDETWorks ${ }^{\mathrm{TM}}$ engineering design and costing software to estimate $\mathrm{AD}$ construction and staffing costs [37]. Supplementary costs were referenced from the RSMeans building construction cost database [52], or via personal communication with WRRF staff.

All costs were classified as either annual or capital costs. Total capital costs are the sum of purchased equipment costs and the associated direct and indirect costs. Direct costs include mobilization, site preparation and electrical, piping, instrumentation, and building requirements. Indirect costs include professional services, miscellaneous and contingency costs, and profit. Direct costs were estimated as a percentage of the purchased equipment price. Indirect costs were estimated as a percentage of the sum of purchased equipment and direct costs. Total annual costs are the sum of operation costs, material costs, chemical costs, and energy costs. Escalation factors were applied to current labor, material, operation, and energy prices to provide an estimate for future years. Escalation factors vary between 
$0 \%$ and $4 \%$ annually depending upon the cost category and scenario. The discount rate utilized for the NPV calculation varies between $3 \%$ and $6 \%$ in the high and low cost scenarios, respectively. Assumed revenues from generated electricity, septage disposal, HSOW disposal, and compost sales also vary between cost scenarios. Direct and indirect cost factors, escalation rates, and formulas used to calculate cost escalation, net present value, and payback period are detailed in SI Section S1.11.

\section{Results}

\subsection{LCA Results}

Figure 2 shows LCIA results by treatment stage for the base legacy WRRF, base upgraded WRRF, and an optimized upgraded WRRF scenario for GCCP, CED, EP, and WU. The optimized scenario corresponds to the high feedstock, high AD performance, and the low EOL emission scenarios. Results are also presented by process contribution for both GCCP and CED. Treatment stage figures aggregate impact according to groupings of unit processes and associated equipment (Table S21) within the WRRF, while process contribution figures aggregate impact according to underlying drivers such as energy use, chemical use, or process emissions. Whiskers bounding the net impact results for the base upgraded WRRF represent the full range of impact results generated by the feedstock-AD-EOL emission scenarios, with scenario parameter values as defined in Table 2 through Table 4 . All upgraded results in the figure are representative of the windrow composting system. GCCP results for the ASP system are included in Figure 3. All scenario LCA results are provided by unit processes in Table S22 and S23 for the legacy WRRF and the upgraded WRRF, respectively.

Study findings in Figure 2c demonstrate that effluent nutrient discharges dominate EP, particularly for the legacy WRRF. Upgrading the WRRF to include MLE biological nutrient removal yields a 37\% reduction in EP results when comparing base scenario results for both systems. Both net CED and GCCP impact results increase in response to system upgrades in the base scenario, by $5 \%$ and $25 \%$, respectively. WU decreases dramatically in response to the small amount of effluent reuse $(4 \%$ of influent) that accompanies the WRRF upgrade, producing a net environmental benefit in this impact category. In addition to avoided water extraction associated with reuse, avoided fertilizer production also yields a net reduction in water use by avoiding water consumption for chemical fertilizer production.

The extent to which environmental benefits are achieved by the optimized scenario is dependent on several management practices. First, it is necessary to fully utilize the available capacity of the AD unit and to supplement municipal sludge with HSOW. Additionally, the high biogas yields that lead to large avoided energy credits in the high AD scenario are predicated on the use of chemically enhanced primary clarification to maximize the quantity and digestibility of volatile solids available in the digester.

The whisker range demonstrates that GCCP and CED impact results of the upgraded WRRF and their relative relationship to those of the legacy system are strongly dependent upon the feedstock-AD-EOL scenario under consideration. For these two impact categories, the maximum reductions in impact results, relative to the legacy base scenario, are $180 \%$ for GCCP and $210 \%$ for CED. In all cases, the minimum impact result is associated with the high feedstock-high AD-low EOL emissions scenario, which is included as the optimized upgraded scenario in Figure 2. Eutrophication potential is less sensitive to the feedstock-AD scenario, demonstrating only a $23 \%$ difference between the maximum and minimum impact results. Water use results respond negligibly to the sensitivity scenarios as effluent reuse dominates results and remains constant across scenarios.

Figure 2e,f shows the reductions in net GCCP and CED, attributable to avoided electricity and natural gas from biogas recovery, avoided drinking water treatment from wastewater reuse, and avoided fertilizer production from compost land application. GCCP of the upgraded WRRF is reduced via the carbon sequestration credit, attributable to compost land application. Collectively, the carbon credit and avoided product benefits reduce gross GCCP and CED of the upgraded WRRF by $46 \%$ 
and $42 \%$, respectively, in the upgraded base scenario. In the absence of compost land application and avoided product benefits, the environmental burdens associated with WRRF upgrades exceed those of the legacy system by $130 \%$ and $70 \%$ for GCCP and CED.

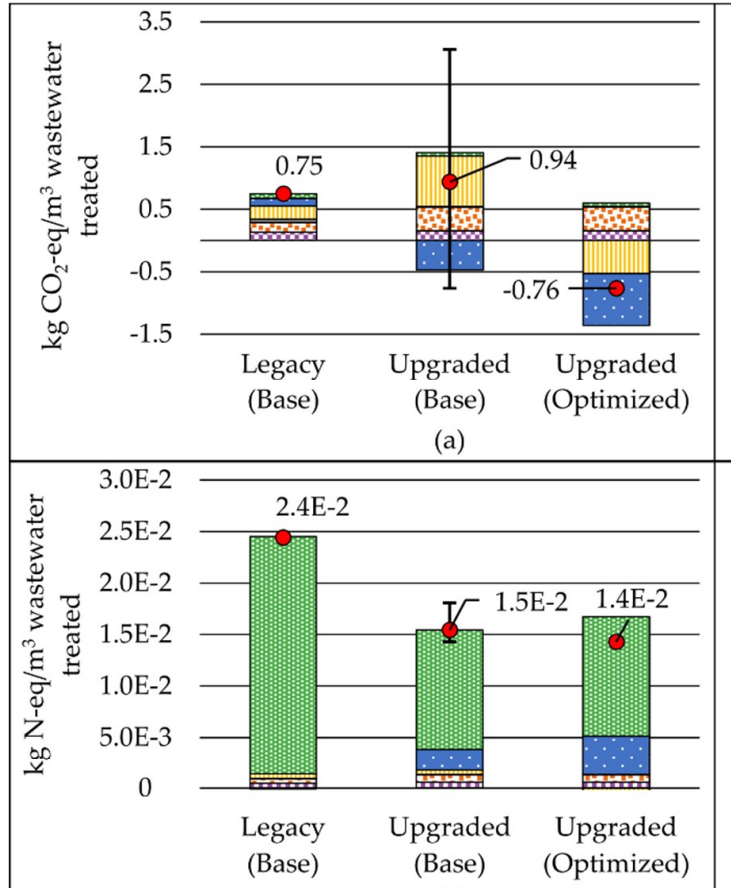

(c)
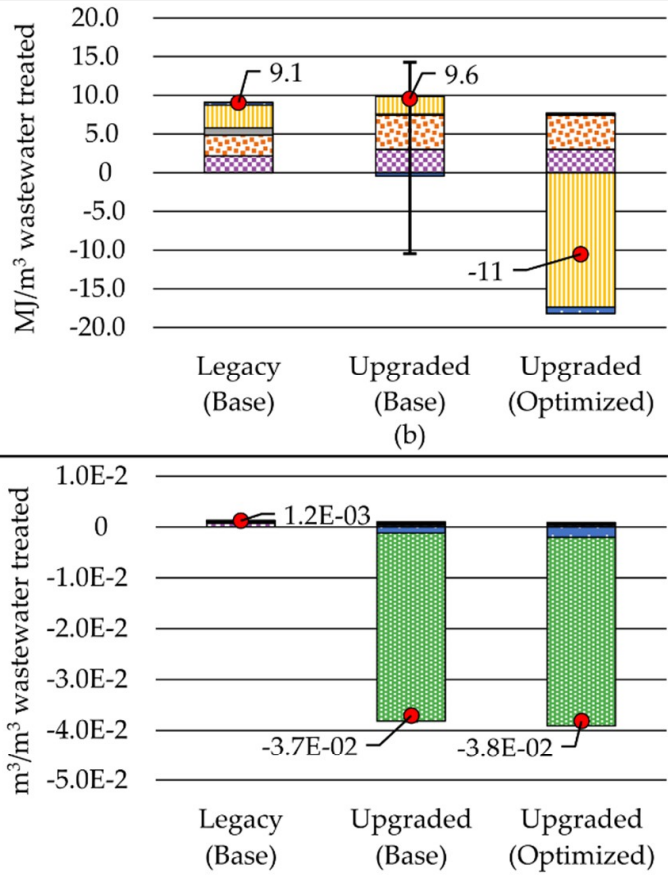

(d)

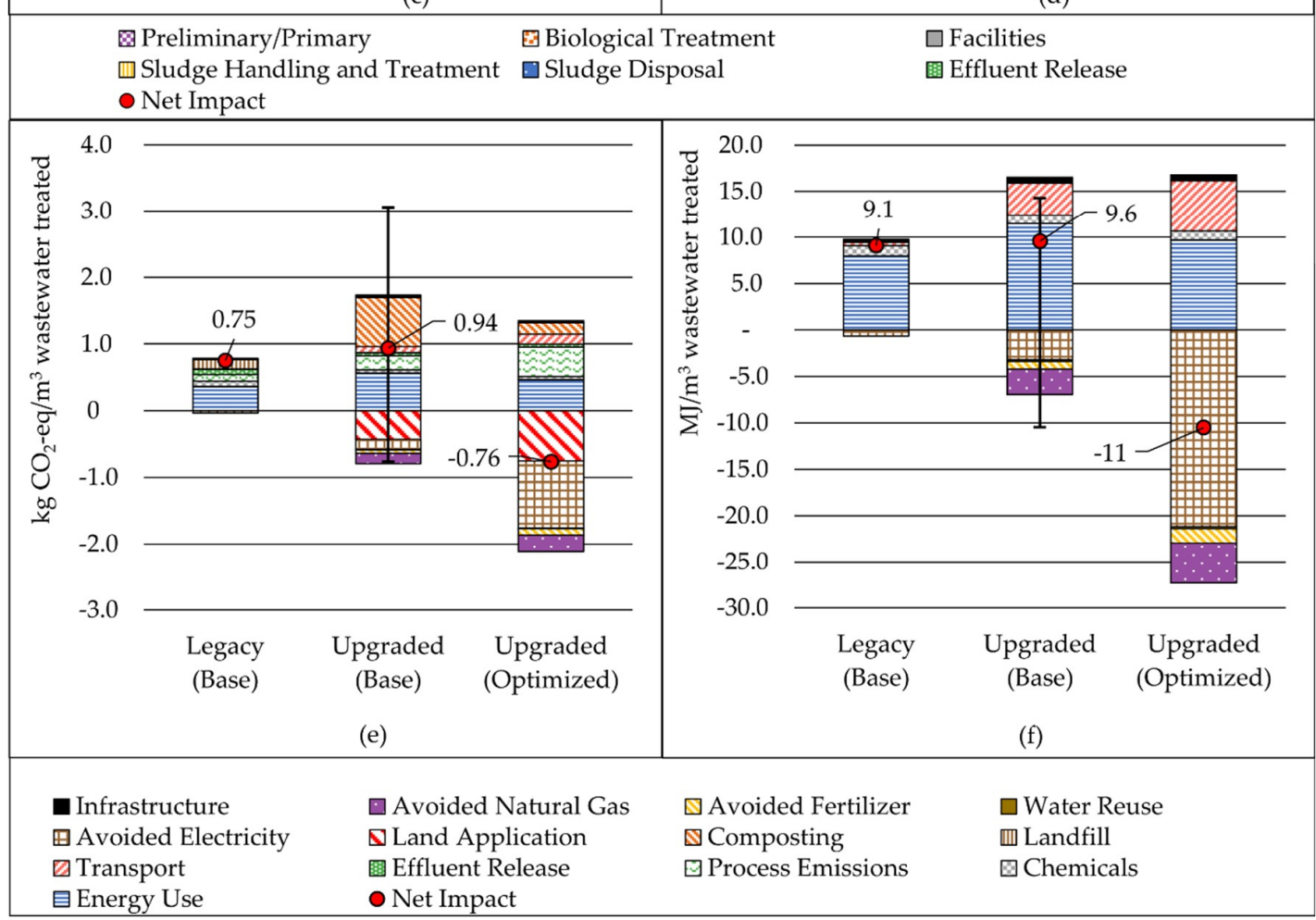

Figure 2. Results by treatment stage for: (a) Global climate change potential; (b) Cumulative energy demand; (c) Eutrophication potential; and (d) Water use; and by process contribution for: (e) Global climate change potential; and (f) Cumulative energy demand. Facilities refers to infrastructure and energy use of administration buildings. Optimized: high feedstock (Table 2)-high AD performance (Table 3)-low EOL emission scenario (Table 4). 


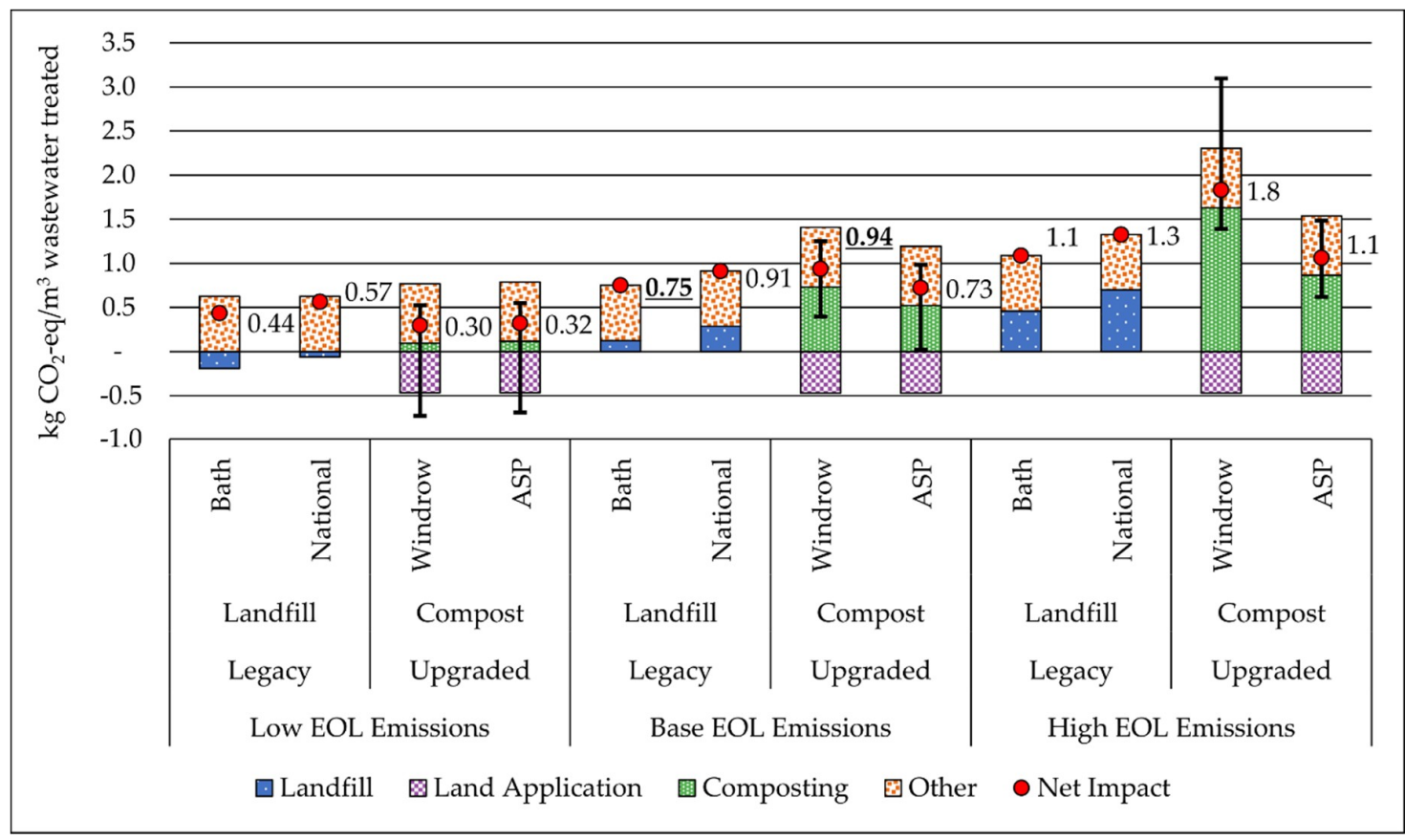

Figure 3. Impact of end-of-life strategy on global climate change potential of legacy and upgraded WRRFs. Whisker bars show the range of results for all feedstock-AD scenarios where applicable. Underlined impact results identify the base scenario results (Tables 2-4). Abbreviations: ASP, aerated static pile; EOL, end-of-life.

Figure 3 shows the effect of the low, base, and high EOL emission scenarios and compost system selection on GCCP impact for the legacy and upgraded WRRFs. The results depicted are associated with the base feedstock-base AD scenario for the upgraded WRRF. We calculated legacy system results assuming methane capture and WTE performance of both the Bath regional and national average landfill. The "other" category in Figure 3 includes all additional GCCP impact associated with treatment processes not associated with EOL processes.

Compost emissions in both the base and high EOL emission scenarios are a dominant contributor to life cycle GHG emissions. The upgraded WRRF reliant upon windrow composting is particularly sensitive to the methane emission factor, as demonstrated by both the range and maximum height of the whisker bars within the high EOL emission scenario. The ASP system demonstrates a more limited sensitivity due to the biofilter, which eliminates methane emissions by oxidizing the methane back to carbon dioxide [53]. Carbon sequestration associated with all systems reduces net GCCP impact and remains relatively consistent across scenarios. The impact of waste disposal for the additional septage processed by the upgraded WRRF is not included for the legacy system and could affect relative impact results between the legacy and upgraded WRRFs. The range of compost emission factors presented in Table 4 is sufficient to cause a shift in composting GCCP impact that pivots between provision of a net benefit to be the single largest contributor to GCCP impact.

A range of EOL emissions is also possible for the Bath regional and national average landfill, which can lead to a similar swing between the provision of net GCCP benefits or considerable relative impact. Benefits attributable to landfilling include avoided energy from landfill gas WTE systems and sequestration of landfilled carbon. All four EOL treatment options yield a net reduction in GCCP impact under the low EOL emission scenario. ASP composting provides the best GCCP performance within the base and high EOL emission scenarios followed by the Bath regional landfill option.

\subsection{LCCA Results}

Life cycle costing reflects the NPV of operating the upgraded WRRF over a 30-year period. Figure 4 presents NPV, in million dollars, for all feedstock-AD scenarios broken down into five cost 
categories: construction, operations, materials, chemicals, and energy. NPV of the upgraded system ranges from 31 to 38 million dollars depending upon utilization and performance of the AD system under base LCCA assumptions. Whisker bars on each column reflect the range of NPV estimates generated by the low and high LCCA scenarios. System NPV is more sensitive to LCCA parameters, particularly revenue fees, as more HSOW is accepted and capacity utilization of the AD units increases. Across all feedstock-AD scenarios, the low cost LCCA scenario yields a percent difference that is $13-44 \%$ below the base cost LCCA NPV.

The NPV of construction costs is approximately 17 million dollars regardless of scenario and is the largest contributor to NPV followed by operations. Operations includes plant staffing costs, ancillary material and facility costs such as waste disposal and professional services. The net contribution of energy costs to system NPV is reduced due to revenue generated via electricity sales and avoided natural gas purchases. The table at the top of Figure 4 lists the AD payback period for all scenarios. The columns in the table correspond to feedstock-AD scenarios in the column chart. Only the low LCCA scenario can generate a payback period for the AD and CHP investment that is less than the 30-year system lifespan. Apart from the discount rate, which is a primary determinant of NPV resulting from the analysis, the payback period is strongly determined by revenue per gallon of septage and HSOW. Assumed revenue ranges from 7.9 to 39 dollars per $\mathrm{m}^{3}$ for HSOW [31] and from 1.9 to 2.6 dollars per $\mathrm{m}^{3}$ for septage [51], and will be determined by local market conditions.

For the base scenario, the life cycle cost of installing and operating the AD, CHP, and composting systems is approximately 11 million dollars, and constitutes $31 \%$ of the systems total NPV. For the high feedstock-high AD-base cost scenario, the life cycle cost of installing and operating these unit processes drops to approximately 5 million dollars due to revenue associated with waste tipping fees and energy cost savings. Installation of these unit processes is not required to meet the new effluent permit guidelines. Other life cycle costs are necessary for continued operation of the WRRF and for upgrades associated with installing biological nutrient removal.

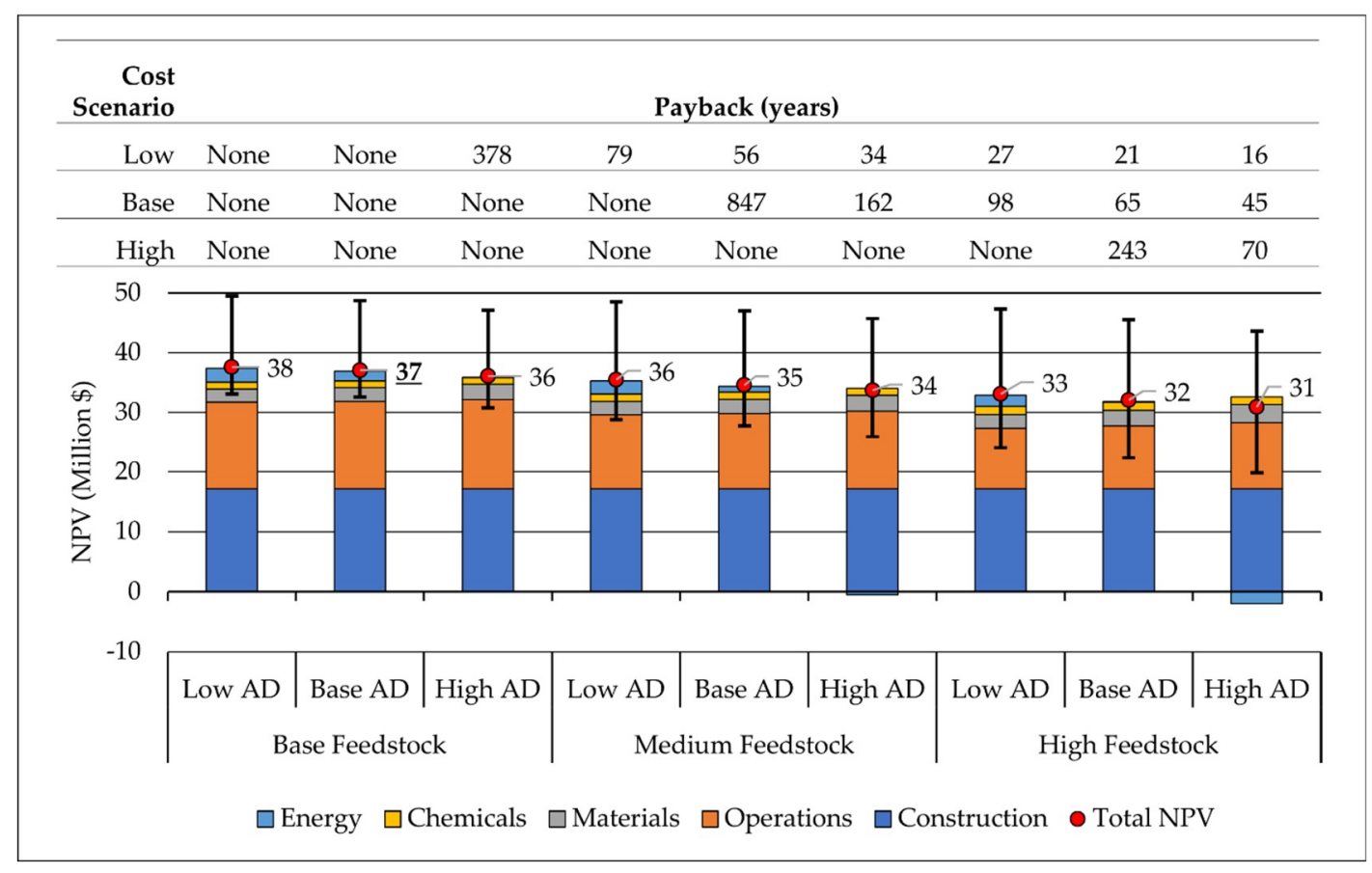

Figure 4. NPV of upgraded WRRF by cost category and AD payback period. Bars show low to high NPV estimate for each feedstock-AD scenario. The underlined impact result identifies the base scenario result (Tables 2-4). Abbreviations: AD, anaerobic digester; NPV, net present value. 


\section{Discussion}

Results demonstrate that capacity utilization and performance of the AD system are determining factors in whether a relative decrease or increase in environmental impact is associated with the WRRF upgrade. Gross LCIA results (Figure 2e,f) reflect the increases in CED and GCCP that accompany increased material and energy requirements for advanced secondary treatment, $\mathrm{AD}$, and composting. The environmental credits attributable to avoided energy products from biogas recovery, avoided fertilizer production, and treated effluent reuse, that characterize the concept of a resource recovery hub, serve to limit the relative increase in net CED and GCCP associated with achieving improved effluent quality within the upgraded base scenario. Results of the scenario analysis demonstrate the potential to realize equivalent GCCP and environmental benefits in CED and WU categories if the full capacity of the $\mathrm{AD}$ system (high feedstock scenario) is utilized assuming base $\mathrm{AD}$ performance.

If high $\mathrm{AD}$ performance is achieved, GCCP of the upgraded treatment plant is less than that of the legacy system, and environmental benefits in the CED and WU impact categories increase. The high $\mathrm{AD}$ performance scenario assumes a marked increase in biogas production associated with high biogas yield estimates for primary sludge from chemically enhanced primary clarification. The pairing of this unit with $\mathrm{AD}$ is intentional in that a higher fraction of volatile solids is removed from the wastewater prior to secondary treatment, which serves the dual purpose of limiting loading to the MLE and preserving those volatile solids for degradation in the $\mathrm{AD}$ where they produce environmental benefits and revenue via energy recovery. While the high estimate of biogas yield associated with chemically enhanced primary clarifier sludge is based on a pilot study, the theoretical performance of this system is promising from an environmental perspective at the 1 MGD scale.

GCCP is the most volatile of the four impact categories and demonstrates multiple dependencies on energy use, EOL emissions, and process emissions from WRRF unit operation and effluent release. Results are particularly sensitive to EOL emission scenarios indicating the importance of carefully considering selection of these treatment options and the subsequent management of composting systems. The ASP composting system demonstrates the lowest sensitivity to EOL emission scenarios and is likely to be the most reliable means of achieving low GCCP impact for WRRFs looking to rely on composting. Results reflect positively on efforts to increase methane capture and WTE capture at landfills around the country.

The LCCA illustrates the difficulty of achieving desirable economic performance of AD at small scales. An AD payback period of less than the 30-year system lifespan was only demonstrated for the three high feedstock-low cost scenarios, due to the higher tipping fees and energy value assumed in the low cost scenario. Despite the challenge of realizing system payback, the trend discovered highlights the benefit, in terms of reduced system NPV, that can result from supplementing municipal solids with HSOW to boost biogas production. Indeed, at larger plant scales with existing digester capacity, economic viability can be achieved more readily [24,54]. At this scale of implementation, however, the environmental benefits associated with $\mathrm{AD}$ come at the expense of increased life cycle costs beyond what would be required only to meet the updated permit nitrogen standards.

Results from comparable LCAs generally support the findings of this study, mainly that the environmental and economic benefits of $\mathrm{AD}$ are best realized when capacity is increased through co-digestion of HSOW. In a study of two larger Australian municipalities, Edwards et al. [23] found that compared to the separate management of sewage sludge and food waste, anaerobic co-digestion could result in a smaller global warming, acidification and eutrophication potential. At a smaller scale, Remy and Jekel [55] showed that the recovery of energy from the co-digestion of source-separated blackwater and household biowaste could lower the cumulative energy demand of waste service provision by $13-26 \%$ compared to conventional activated sludge treatment and organics incineration. Evaluating the entire municipal water cycle, Xue et al. [5] compared traditional centralized water and wastewater services to several "fit-for-purpose" scenarios. Their results showed that the electricity generated from blackwater and food waste co-digestion could offset at least $40 \%$ of life cycle energy consumption and result in lower eutrophication impacts. All studies identified significant sensitivities 
to AD capacity and organics loading. This research provides guidance for other small communities as they consider WRRF upgrades and in their long-term sustainability efforts. The analysis demonstrates the potential environmental benefits of strategies aimed at resource recovery. Findings highlight the importance of conscientious process selection and management of WRRF operations if relative reductions in environmental impact are to be reliably achieved.

\section{Conclusions}

- Installation of AD and operation as a resource recovery hub yielded reductions in GCCP and CED that can offset increased energy and material requirements of enhanced nutrient removal.

- Sensitivity results demonstrated the environmental benefit of utilizing the full capacity of AD facilities by accepting HSOW and pursuing best management practices to achieve high AD operation performance while minimizing potential for GHG generation at composting facilities.

- The pairing of chemically enhance primary clarification with AD demonstrated the potential to increase biogas production, reducing overall plant environmental burdens.

- At the 1 MGD ( $3800 \mathrm{~m}^{3}$ / day) scale, realization of environmental benefits from WRRF upgrades and a focus on resource recovery strategies are more reliably attainable than a monetary return on investment.

Supplementary Materials: The following are available online at http:/ /www.mdpi.com/2071-1050/10/10/3546/ s1, Word File: Bath WRRF Supplementary Tables and Figures; Excel File: Bath WRRF Results File.

Author Contributions: This paper is a result of the collaborative efforts of the listed authors. The following contributions were made: Conceptualization, J.G., X.C.M. and J.T.; Methodology, S.C., B.M., X.C.M. and J.T.; Validation, S.C., X.C.M., J.T., M.N. and L.F.; Formal Analysis, B.M. and S.C.; Investigation, B.M. and S.C.; Writing-Original Draft Preparation, B.M., S.C. and X.C.M.; Writing-Review and Editing, all listed authors; Visualization, B.M. and S.C.; Supervision, J.G. and X.C.M.; and Project Administration, X.C.M., D.B. and J.G.

Funding: This research was funded by the EPA Office of Research and Development's Safe and Sustainable Water Resources Program. The research was supported by EPA contracts EP-C-12-021 and EP-C-16-015.

Disclaimer: The views expressed herein are strictly the opinions of the authors and in no manner represent or reflect current or planned policy by the federal agencies. Mention of trade names or commercial products does not constitute endorsement or recommendation for use. The information and data presented in this product were obtained from sources that are believed to be reliable. The authors declare no competing financial interest.

Acknowledgments: Kim Miller and Guy Hallgren provided insight and primary data on the Bath, NY wastewater treatment plant operations and infrastructure for both the legacy and upgraded systems investigated. Engineering design of treatment plant upgrades was performed by personnel from Conestoga-Rovers \& Associates, now a division of GHD Group. Lori Stone of Water Environment \& Reuse Foundation as well as Pradeep Jangbari of New York State Department of Environmental Conservation provided technical review comments. Janet Mosley and Jessica Gray of Eastern Research Group provided technical input and review of the life cycle inventory and cost analysis. Sam Arden of Eastern Research group provided a literature review and summary of past LCA work looking at wastewater treatment, anaerobic digestion, and co-digestion.

Conflicts of Interest: The authors declare no conflict of interest.

\section{References}

1. Ma, C.; Xue, X.; Gonzalez-Mejia, A.; Garland, J.; Cashdollar, J. Sustainable Water Systems for the City of Tomorrow-A Conceptual Framework. Sustainability 2015, 7, 12071-12105. [CrossRef]

2. U.S. Environmental Protection Agency National Pollutant Discharge Elimination System (NPDES): Nutrient Permitting. Available online: https:/ / www.epa.gov/npdes/nutrient-permitting (accessed on 6 September 2018).

3. ASCE (American Society of Civil Engineers) 2017 Infrastructure Report Card: America's Grades. Available online: https:/ / www.infrastructurereportcard.org/americas-grades / (accessed on 6 September 2018).

4. Schoen, M.; Hawkins, T.; Xue, X.; Ma, C.; Garland, J.; Ashbolt, N.J. Technologic resilience assessment of coastal community water and wastewater service options. Sustain. Water Qual. Ecol. 2015, 6, 75-87. [CrossRef] 
5. Xue, X.; Schoen, M.E.; Ma, X.; Hawkins, T.R.; Ashbolt, N.J.; Cashdollar, J.; Garland, J. Critical insights for a sustainability framework to address integrated community water services: Technical metrics and approaches. Water Res. 2015, 77, 155-169. [CrossRef] [PubMed]

6. Augustin, K.; Skambraks, A.K.; Li, Z.; Giese, T.; Rakelmann, U.; Meinzinger, F.; Schonlau, H.; Günner, C. Towards sustainable sanitation-The Hamburg Water Cycle in the settlement Jenfelder Au. Water Sci. Technol. 2014, 14, 13-21. [CrossRef]

7. Grant, S.B.; Saphores, J.D.; Feldman, D.L.; Hamilton, A.J.; Fletcher, T.D.; Cook, P.L.M. Taking the "Waste” Out of "Wastewater" for human water security and ecosystem sustainability. Science 2012, 337, 681-686. [CrossRef] [PubMed]

8. Guest, J.S.; Skerlos, S.J.; Barnard, J.L.; Beck, M.B.; Daigger, G.T.; Hilger, H.; Jackson, S.J.; Karvazy, K.; Kelly, L.; Macpherson, L.; et al. A new planning and design paradigm to achieve sustainable resource recovery from wastewater. Environ. Sci. Technol. 2009, 43, 6126-6130. [CrossRef] [PubMed]

9. McCarty, P.L.; Bae, J.; Kim, J. Domestic wastewater treatment as a net energy producer-Can this be achieved? Environ. Sci. Technol. 2011, 45, 7100-7106. [CrossRef] [PubMed]

10. U.S. Environmental Protection Agency. Case Study Primer for Participant Discussion: Biodigesters and Biogas; U.S. Environmental Protection Agency: Washington, DC, USA, 2012.

11. Berger, M.; Finkbeiner, M. Water footprinting: How to address water use in life cycle assessment? Sustainability 2010, 2, 919-944. [CrossRef]

12. Muñoz, I.; Rodríquez, A.; Rosal, R.; Fernández-Alba, A.R. Life cycle assessment of urban wastewater reuse with ozonation as tertiary treatment: A focus on toxicity-related impacts. Sci. Total Environ. 2009, 407, 1245-1256. [CrossRef] [PubMed]

13. Hester, E.T.; Little, J.C. Measuring environmental sustainability of water in watersheds. Environ. Sci. Technol. 2013, 47, 8083-8090. [CrossRef] [PubMed]

14. Fulcher, J. Changing the Terms. Available online: https://news.wef.org/changing-the-terms/ (accessed on 3 August 2018).

15. New York State Department of Environmental Conservation. State Pollutant Discharge Elimination System Permit for Village of Bath Wastewater Treatment Plant; New York State Department of Environmental Conservation: New York, NY, USA, 2014.

16. Chesapeake Bay Foundation about the Bay: The Issues. Available online: http://www.cbf.org/about-thebay/issues (accessed on 24 May 2017).

17. Conestoga-Rovers and Associates. Village of Bath WWTP Upgrades Final Engineering Report; Bath Electric, Gas \& Water Systems: Bath, NY, USA, 2015.

18. Comela, R. Navalis Construction Announces Completion of Renewable Landfill Gas-to-Energy Plant in Upstate New York; Navalis Construction: Rochester, NY, USA, 2010.

19. Tchobanoglous, G.; Burton, F.L.; Stensel, H.D.; Tsuchihashi, R.; Abu-Orf, M.; Bowden, G.; Pfrang, W. Wastewater Engineering: Treatment and Resource Recovery, 5th ed.; McGraw-Hill Education: New York, NY, USA, 2014; ISBN 978-0-07-340118-8.

20. Cornejo, P.K.; Zhang, Q.; Mihelcic, J.R. How does scale of implementation impact the environmental sustainability of wastewater treatment integrated with resource recovery? Environ. Sci. Technol. 2016, 50, 6680-6689. [CrossRef] [PubMed]

21. Machado, A.P.; Urbano, L.; Brito, A.G.; Janknecht, P.; Salas, J.J.; Nogueira, R. Life cycle assessment of wastewater treatment options for small and decentralized communities. Water Sci. Technol. 2007, 56, 15-22. [CrossRef] [PubMed]

22. Chiu, S.L.H.; Lo, I.M.C.; Woon, K.S.; Yan, D.Y.S. Life cycle assessment of waste treatment strategy for sewage sludge and food waste in Macau: Perspectives on environmental and energy production performance. Int. J. Life Cycle Assess. 2016, 21, 176-189. [CrossRef]

23. Edwards, J.; Othman, M.; Crossin, E.; Burn, S. Anaerobic co-digestion of municipal food waste and sewage sludge: A comparative life cycle assessment in the context of a waste service provision. Bioresour. Technol. 2017, 223, 237-249. [CrossRef] [PubMed]

24. Krupp, M.; Schubert, J.; Widmann, R. Feasibility study for co-digestion of sewage sludge with OFMSW on two wastewater treatment plants in Germany. Waste Manag. 2005, 25, 393-399. [CrossRef] [PubMed] 
25. Righi, S.; Oliviero, L.; Pedrini, M.; Buscaroli, A.; Della Casa, C. Life Cycle Assessment of management systems for sewage sludge and food waste: Centralized and decentralized approaches. J. Clean. Prod. 2013, 44, 8-17. [CrossRef]

26. US EPA, O. Small Wastewater Systems Research. Available online: https:/ /www.epa.gov/water-research/ small-wastewater-systems-research-0 (accessed on 25 September 2018).

27. ISO. ISO 14044: 2006 Environmental Management_Life Cycle Assessment_Requirements and Guidelines; ISO 14044; The International Organization for Standardization: Geneva, Switzerland, 2006; p. 54.

28. BEGWS (Bath Electric Gas \& Water Systems). Bath Wastewater Treatment Plant Influent and Effluent Water Quality Data: October 2011 to November 2015; BEGWS: Bath, NY, USA, 2011-2015.

29. U.S. Environmental Protection Agency. Inventory of U.S. Greenhouse Gas Emissions and Sinks: 1990-2013; U.S. Environmental Protection Agency: Washington, DC, USA, 2015.

30. Research Triangle Institute. Greenhouse Gas Emissions Estimation Methodologies for Biogenic Emissions from Selected Source Categories: Solid Waste Disposal, Wastewater Treatment, Ethanol Fermentation; U.S. Environmental Protection Agency: Washington, DC, USA, 2010.

31. Appleton, A.R.; Rauch-Williams, T. Co-Digestion of Organic Waste Addressing Operational Side-Effects; Water Environment Research Foundation: Alexandria, VA, USA, 2017.

32. Wiser, J.R.; Schettler, J.W.; Willis, J.L. Evaluation of Combined Heat and Power Technologies for Wastewater Treatment Facilities; U.S. Environmental Protection Agency: Washington, DC, USA, 2010.

33. SYLVIS Environmental. The Biosolids Emissions Assessment Model (BEAM); Canadian Council of Ministers of the Environment: Winnipeg, MB, Canada, 2011.

34. Hellmann, B.; Zelles, L.; Palojarvi, A.; Bai, Q. Emission of climate-Relevant trace gases and succession of microbial communities during open-Windrow composting. Appl. Environ. Microbiol. 1997, 63, 1011-1018. [PubMed]

35. Hellebrand, H.J. Emission of nitrous oxide and other trace gases during composting of grass and green waste. J. Agric. Eng. Res. 1998, 69, 365-375. [CrossRef]

36. Fukumoto, Y.; Osada, T.; Hanajima, D.; Haga, K. Patterns and quantities of $\mathrm{NH}_{3}, \mathrm{~N}_{2} \mathrm{O}$ and $\mathrm{CH}_{4}$ emissions during swine manure composting without forced aeration-Effect of compost pile scale. Bioresour. Technol. 2003, 89, 109-114. [CrossRef]

37. Hydromantis. CAPDETWorks Version 3.0 Software: Rapid Design and Costing Solution for Wastewater Treatment Plants; Hydromantis Environmental Software Solution: Hamilton, ON, Canada, 2014.

38. CDM Smith. Technical Memorandum Report Greater Lawrence Sanitary District Organics to Energy Feasibility Study; CDM Smith: Boston, MA, USA, 2013; p. 95.

39. Czepiel, P.M.; Crill, P.M.; Harriss, R.C. Nitrous oxide emissions from municipal wastewater treatment. Environ. Sci. Technol. 1995, 29, 2352-2356. [CrossRef] [PubMed]

40. Intergovernmental Panel on Climate Change. IPCC Guidelines for National Greenhouse Gas Inventories, Prepared by the IPCC, National Greenhouse Gas Inventories Programme; IGES: Kanagawa, Japan, 2006; ISBN 4-88788-032-4.

41. Czepiel, P.M.; Crill, P.M.; Harriss, R.C. Methane emissions from municipal wastewater treatment processes. Environ. Sci. Technol. 1993, 27, 2472-2477. [CrossRef]

42. Daelman, M.R.; van Voorthuizen, E.M.; van Dongen, L.G.; Volcke, E.; van Loosdrecht, M.C. Methane and nitrous oxide emissions from municipal wastewater treatment-Results from a long-Term study. Water Sci. Technol. 2013, 67, 2350-2355. [CrossRef] [PubMed]

43. Chandran, K. Greenhouse Nitrogen Emissions from Wastewater Treatment Operation: Phase I; Water Environment Research Foundation: Alexandria, VA, USA, 2012; ISBN 978-1-78040-481-3.

44. Smith, K.A.; Jeffrey, W.A.; Metcalfe, J.P.; Sinclair, A.H.; Williams, J.R. Nutrient Value of Digestate from Farm-Based Biogas Plants; Scottish Executive Environmental and Rural Affairs Department: Edinburgh, UK, 2007.

45. NREL U.S. Life Cycle Inventory Database 2012. Available online: https://www.lcacommons.gov/lcacollaboration/search/page=1\&group=National_Renewable_Energy_Laboratory (accessed on 1 October 2018).

46. Frischknecht, R.; Jungbluth, N.; Althaus, H.-J.; Doka, G.; Dones, R.; Heck, T.; Hellweg, S.; Hischier, R.; Nemecek, T.; Rebitzer, G.; et al. The ecoinvent database: Overview and methodological framework. Int. J. Life Cycle Assess. 2005, 10, 3-9. [CrossRef]

47. Bare, J. TRACI 2.0: The Tool for the reduction and assessment of chemical and other environmental impacts. Clean Technol. Environ. Policy 2011, 13, 687-696. [CrossRef] 
48. Bare, J.; Norris, G.A.; Pennington, D.W.; McKone, T. TRACI: The Tool for the reduction and assessment of chemical and other environmental Impacts. J. Ind. Ecol. 2002, 6, 49-78. [CrossRef]

49. Goedkoop, M.; Heijungs, R.; Huijbregts, M.; De Schryver, A.; Struijs, J.; van Zelm, R. ReCiPe 2008: A Life Cycle Impact Assessment Method Which Comprises Harmonised Category Indicators at the Midpoint and the Endpoint Level: Report 1 Characterization; ReCiPe: Bilthoven, The Netherlands, 2009.

50. Althaus, H.-J.; Bauer, C.; Doka, G.; Dones, R.; Frischknecht, R.; Hellweg, S.; Humbert, S.; Jungbluth, N.; Kollner, T.; Loerincik, Y.; et al. Implementation of Life Cycle Impact Assessment Methods: Data v2.2 (2010); Ecoinvent Centre: St. Gallen, Switzerland, 2010.

51. GHD Engineering. Life Cycle Cost Analysis Evaluation: Preliminary and Primary Treatment; Bath Electric, Gas \& Water Systems: Bath, NY, USA, 2016.

52. RSMeans; Building Construction Cost Data 2016. Available online: https://www.rsmeans.com/ (accessed on 1 October 2018).

53. Canadian Council of Ministers of the Environment. Biosolids Emissions Assessment Model (BEAM): User Guide; Canadian Council of Ministers of the Environment: Winnipeg, MB, Canada, 2009.

54. Bolzonella, D.; Battistoni, P.; Susini, C.; Cecchi, F. Anaerobic codigestion of waste activated sludge and OFMSW: The experiences of Viareggio and Treviso plants (Italy). Water Sci. Technol. 2006, 53, $203-211$. [CrossRef] [PubMed]

55. Remy, C.; Jekel, M. Energy analysis of conventional and source-separation systems for urban wastewater management using life cycle assessment. Water Sci. Technol. 2012, 65, 22-29. [CrossRef] [PubMed]

(C) 2018 by the authors. Licensee MDPI, Basel, Switzerland. This article is an open access article distributed under the terms and conditions of the Creative Commons Attribution (CC BY) license (http:/ / creativecommons.org/licenses/by/4.0/). 